\title{
Development of an airborne ice sounding radar front-end
}

\author{
Krozer, Viktor; Hernandez, C C; Vazquez Roy, J L; Vidkjær, Jens; Dall, Jacob
}

Published in:

European Radar Conference, 2007. EuRAD 2007.

Link to article, DOI:

10.1109/EURAD.2007.4404922

Publication date:

2007

Document Version

Publisher's PDF, also known as Version of record

Link back to DTU Orbit

Citation (APA):

Krozer, V., Hernandez, C. C., Vazquez Roy, J. L., Vidkjær, J., \& Dall, J. (2007). Development of an airborne ice sounding radar front-end. In European Radar Conference, 2007. EURAD 2007. IEEE.

https://doi.org/10.1109/EURAD.2007.4404922

\section{General rights}

Copyright and moral rights for the publications made accessible in the public portal are retained by the authors and/or other copyright owners and it is a condition of accessing publications that users recognise and abide by the legal requirements associated with these rights.

- Users may download and print one copy of any publication from the public portal for the purpose of private study or research.

- You may not further distribute the material or use it for any profit-making activity or commercial gain

- You may freely distribute the URL identifying the publication in the public portal

If you believe that this document breaches copyright please contact us providing details, and we will remove access to the work immediately and investigate your claim. 


\title{
Development of an Airborne Ice Sounding Radar Front-End
}

\author{
Viktor Krozer ${ }^{\#}$, Carlos Cilla Hernandez ${ }^{\#}$, José Luis Vazquez Roy ${ }^{*}$, Jens Vidkjaer ${ }^{\#}$, and Jørgen Dall ${ }^{\#}$ \\ \# Electromagnetic Systems, Technical University Denmark, Ørstedplads 348, \\ 2800 Kgs. Lyngby, Denmark, vk@,oersted.dtu.dk \\ * on leave from Dpto. Teoría de la Señal y Comunicaciones, Escuela Politecnica Superior, \\ Universidad Carlos III de Madrid, Av. Universidad 30, 28911 Madrid, Spain, jvazquez@tsc.uc3m.es
}

\begin{abstract}
This paper describes the design of an airborne P-band ice sounding radar. The ice sounder design features a microstrip antenna array with a relative operating bandwidth of $20 \%$, compact RF components, a high efficiency high-power LDMOS power amplifier with $>\mathbf{6 0} \%$ power-added efficiency across a relative bandwidth of $20 \%$ at a center frequency of $435 \mathrm{MHz}$, and a digital signal generation and acquisition unit. Furthermore, we demonstrate broadband performance of our left-handed/right-handed out-of-phase power dividers. In 2008 the first data acquisition campaign will take place in Greenland.
\end{abstract}

\section{INTRODUCTION}

The European Space Agency has initiated a demonstrator project with the aim to develop an airborne P-band ice sounding radar ( $\mathrm{P}$-sounder), which shall enable an assessment of the detection of internal ice layers, reflection from the base of the ice sheet and validation of data processing algorithms.

Key parameters of the instrument are listed in Table 1, and additional specifications and requirements are found in [1]. The system sensitivity is sufficient to detect the bedrock through $4 \mathrm{~km}$ of ice and to detect deep ice layers. Pulse-topulse coherence helps improving the sensitivity.

\section{Table 1 P-Sounder Specifications}

\begin{tabular}{ll}
\hline Center frequency & $435 \mathrm{MHz}$ \\
Bandwidth (goal) & $85 \mathrm{MHz}$ \\
Polarization & quad \\
Maximum pulse length & $50 \mu \mathrm{s}$ \\
Peak power & $100-300 \mathrm{~W}$ \\
Maximum PRF & $20 \mathrm{kHz}$ \\
Operating altitude & $3500 \mathrm{~m}$ \\
\hline
\end{tabular}

Surface clutter suppression is implemented with the help of synthetic aperture processing. Full polarimetry is justified by ice physics and special care is taken to achieve good calibration and stability [1]. The P-sounder features an experimental coherent clutter suppression capability based on a multiple-phase-centre antenna. The technique is similar to that of the MARSIS sounder [2].

A system analysis based on the envisioned flight geometry, system specifications, and data processing suggests that a peak power of $100 \mathrm{~W}$ in combination with an antenna with four patches in the across-track direction is sufficient to detect the bedrock down to $4 \mathrm{~km}$. Based on very good experience with the airborne EMISAR system [3] the internal calibration is done by looping the generated pulses around as close to the antennas as possible and back through the receiver channel.
This way the calibration is carried out in an almost perfect way by using exactly the same signal as used during normal operation.

The paper first describes the newly developed antenna array and subsequently the key RF components. Both experimental results and simulations agree well in most cases and the relative bandwidth requirement of $>20 \%$ is realized with most components.

\section{ANTENNA DESIGN}

A wideband probe-fed dual-linear polarisation wideband microstrip patch antenna array has been developed for the Psounder. The microstrip patch antenna has been extensively employed in EMISAR L-band synthetic aperture radar (SAR) with very good performance [1],[4],[5], however at a reduced relative bandwidth. An improved bandwidth of this antenna has been presented in [5] with very good return loss.

A P-band sounder microstrip patch antenna has been developed by DLR with $28 \%$ relative bandwidth and 350 $\mathrm{MHz}$ center frequency [6], but with a trade-off in return loss. Similar antennas have been developed by Saab Ericsson [7] and at lower frequencies by JPL [8].

As a consequence of these previous developments we have decided to employ a microstrip patch antenna with a probe-fed co-planar active patch excitation and a parasitic patch. Such a feeding structure has been proposed in [9]. The probe fed minimizes the cross-coupling and cross-polarization levels.

A drawing of a single patch is given in Figure 1. In contrast to a standard design we employ a cavity around the substrate and coplanar patch excitation [9]. We have observed that this greatly improves the bandwidth and cross-coupling levels. The return loss is better than $15 \mathrm{~dB}$ from $379 \mathrm{MHz}$ to 480 $\mathrm{MHz}$. The cross-coupling between the ports is predicted to be $-20 \mathrm{~dB}$ in the center of the band and increases to around -14 $\mathrm{dB}$ on the band edges.

The results for the return loss and cross-coupling are presented in Figure 2 for both polarizations. It should be emphasized that a fine mesh, together with a finite conductivity for the metal, and finite ground plane are necessary in order to obtain very good agreement between measured and simulated results.

The measured and simulated radiation patterns for the Eplane and the H-plane in the horizontal polarisation are presented in Figure 3 for a number of frequencies inside the operating band. The simulations have been included only at 
$435 \mathrm{MHz}$ for clarity. At the respective frequency the radiation patterns follow closely the predicted ones for both planes. There is a slight asymmetry in the E-plane pattern in both the simulations and the measurements. This can be due to the excitation patch, but is much more pronounced in the simulations.

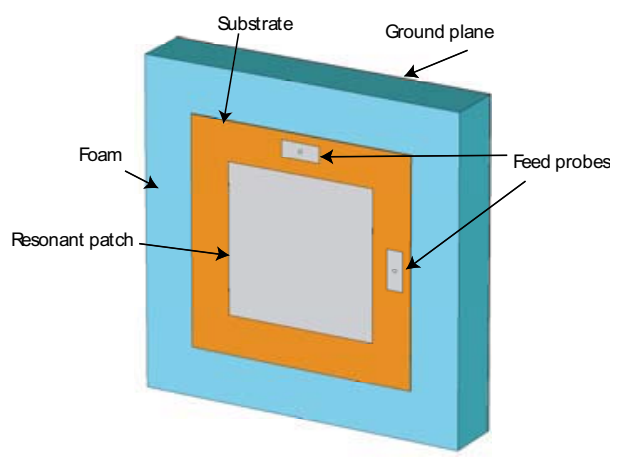

Figure 1: Drawing of the developed active patch antenna.
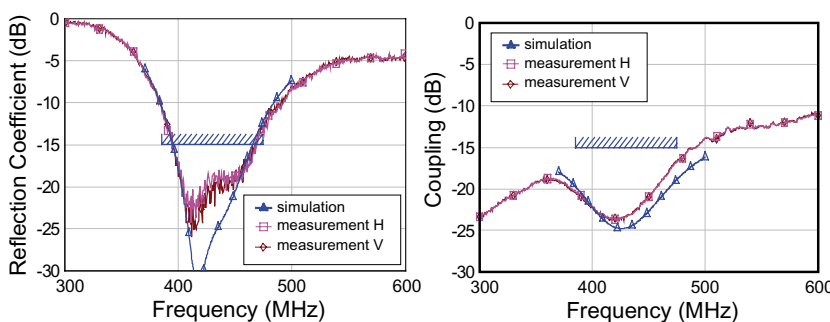

Figure 2: Comparison between simulated and measured results for the cavitybacked single patch antenna. Observe that the measured results in the figure include both $\mathrm{H}$ and $\mathrm{V}$ ports.
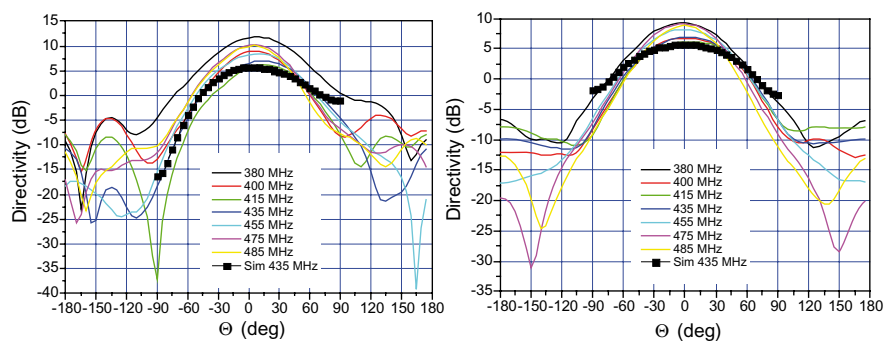

Figure 3: Measured and simulated radiation pattern for the cavity-backed single patch antenna in the E-plane (left) and H-plane (right) for the horizontal polarisation and number of frequencies.

One of the advantages of the structure developed in this work is the ease of assembly in a building brick principle, as each single antenna has its own cavity box, illustrated in Figure 4. The figure also shows that there is a negligible variation in the impedance between the individual ports for both polarizations. A bandwidth of approximately $80 \mathrm{MHz}$ at $\mathrm{RL}>15 \mathrm{~dB}$ has been achieved, which suffices the $20 \%$ relative bandwidth requirement. The array employs a parasitic second patch at a distance of $30 \mathrm{~mm}$ from the active patch. The active patch size is $213 \mathrm{~mm}$, foam thickness is $70 \mathrm{~mm}$, the parasitic patch size is $180 \mathrm{~mm}$, the excitation patch size is $19 \mathrm{~mm} \times$ $39.5 \mathrm{~mm}$, and the distance between the excitation and the active patch is $3 \mathrm{~mm}$.
The simulated radiation pattern is depicted in Figure 5 . We can see that the sidelobe level is around $-15 \mathrm{~dB}$ below main lobe and the cross-polarisation maxima are at angles above $50^{\circ}$ and do not impact the antenna array performance.
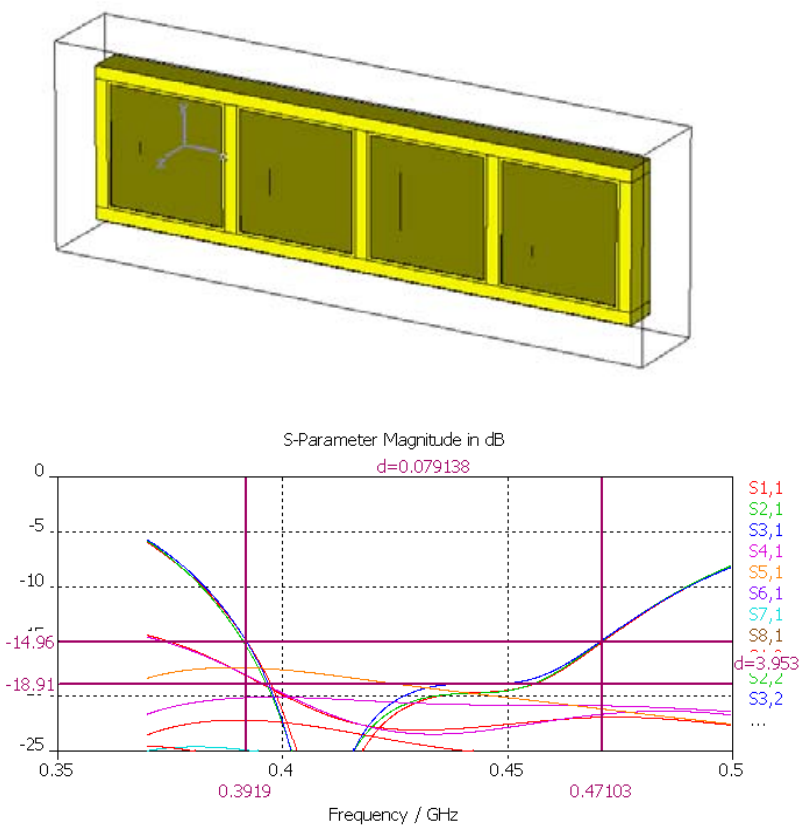

Figure 4: Drawing of the antenna array built with 4 single patch cavity backed antennas and the return loss and cross-coupling for all ports of the antenna.

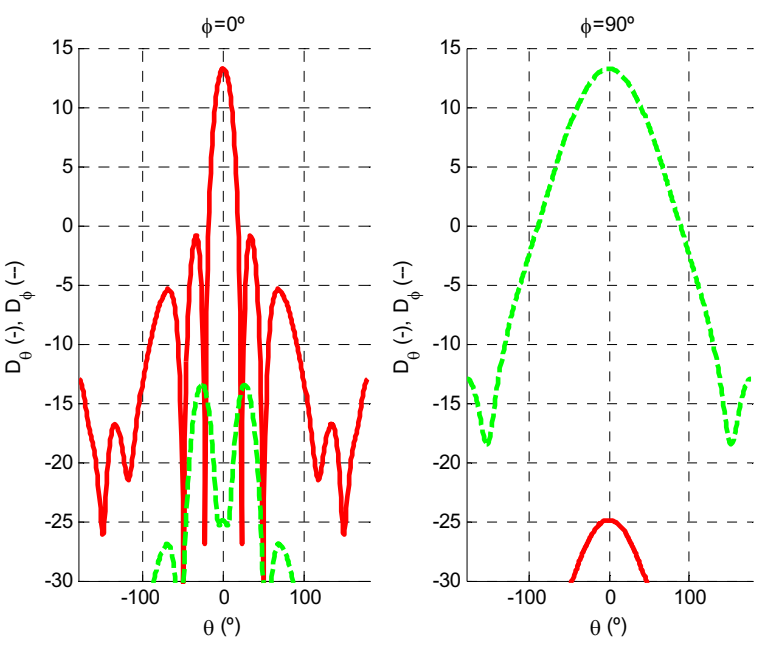

Figure 5: Simulated antenna pattern of the antenna array for horizontal polarisation in E-plane and H-plane, respectively.

\section{RF FRONT-END COMPONENTS}

The transmitter front-end will be composed of a high power high-efficiency amplifier (HPA), a high power PIN switch, a slow high power relay for calibration mode, a circulator, and power splitters. The power amplifier is assumed to have sufficient gain to amplify directly the signal available from the digital signal generator. The receiver front-end is composed of a a circulator, a limiter a low-noise amplifier, a bandpass filter and a variable gain amplifier. The LNA has not sufficient gain 
in order to be able to drive directly the $\mathrm{A} / \mathrm{D}$ converters in the digital acquisition unit, so a variable gain amplifier is used to adjust the receiver gain depending on the operation mode of the radar.

\section{A. Power Divider}

We have developed lumped element Wilkinson type inphase and out-of-phase power dividers. Such realizations have been presented earlier [10], [11], but did not have the RF power handling capabilities. Out-of-phase lumped element power dividers have also been reported earlier [12] including dividers using metamaterial lines [13]. The design here is based on metamaterial lines, but exhibits a better bandwidth performance and can handle higher powers with considerably less losses.

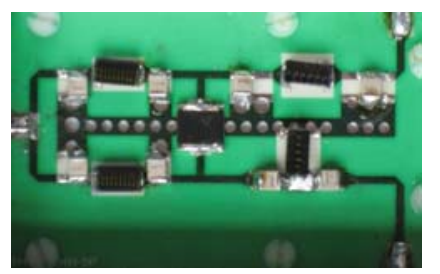

Figure 6: Photograph of the fabricated $180^{\circ}$ lumped element Wilkinson divider.

Figure 6 shows a photograph of the out-of-phase Wilkinson divider employing left-handed/right-handed section to realize the $180^{\circ}$ phase shift between the ports 2 and 3 . The dimensions of both divider circuits are around $60 \mathrm{~mm} \times 40$ $\mathrm{mm}$.
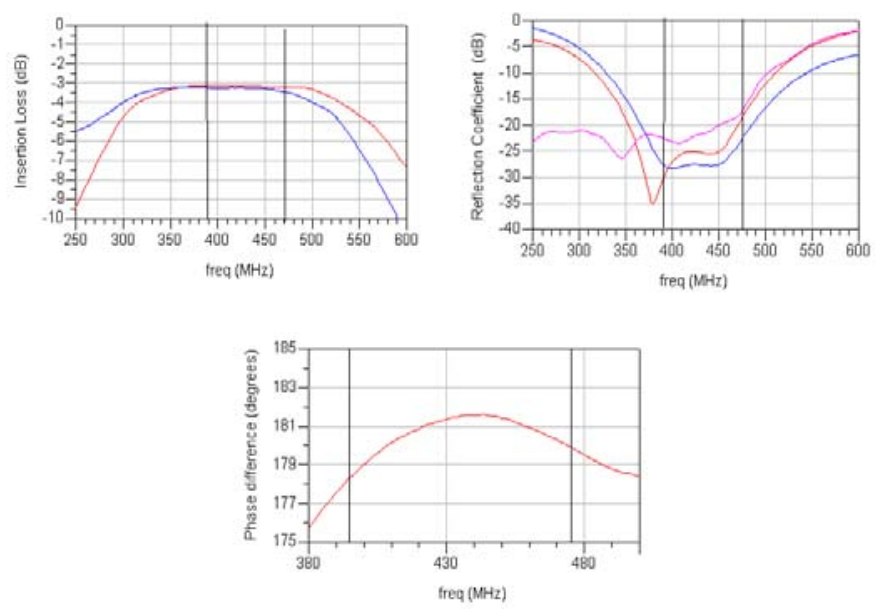

Figure 7: Measured insertion loss, reflection coefficient and phase difference for the $180^{\circ}$ Wilkinson divider.

This network is a compromise between amplitude and phase unbalance. The phase difference between the ports has been adjusted to the very small value of around $4^{0}$, at the expense of an amplitude unbalance of $0.23 \mathrm{~dB}$. The circuit inevitably exhibits higher losses as compared with the standard Wilkinson divider realized here (insertion loss 0.2 $\mathrm{dB}$ ), but the measured losses remain below $0.5 \mathrm{~dB}$, comparable to a $180^{\circ}$ coupler. The return loss is provided in Figure 7 and is better than $15 \mathrm{~dB}$ across the full band.
The phase difference has a maximum measured variation of $2^{0}$, which is an excellent value and matches perfectly $180^{\circ}$ at the center frequency. Even better results, amplitude difference of $0.1 \mathrm{~dB}$, insertion loss of $0.2 \mathrm{~dB}$, phase balance $<1^{0}$ over the frequency band has been achieved for the in-phase lumped element Wilkinson divider.

The necessary $20 \%$ bandwidth is realized for both circuits with a return loss better than $15 \mathrm{~dB}$ and power handling capabilities up to around $75 \mathrm{~W} \mathrm{CW}$ microwave power.

\section{B. High Efficiency Power Amplifier}

The frequency of operation and the bandwidth of $80 \mathrm{MHz}$ strongly limit the amount of commercially available amplifiers. Two solutions have been developed and characterized. One is based on the Mitsubishi power module 45H4047 exhibiting input and output matching, but a low power-added efficiency and is operating from a $12 \mathrm{~V}$ power supply. The other HPA is based on a proprietary design for very high PAE of up to $65 \%$ with a $28 \mathrm{~V}$ bias voltage.

We have developed a high efficiency power amplifier based on series matching and class B operation. The amplifier is based on two stages, a driver and a power stage using LDMOS MRF373. The schematic representation of the amplifier is given in Figure 8.

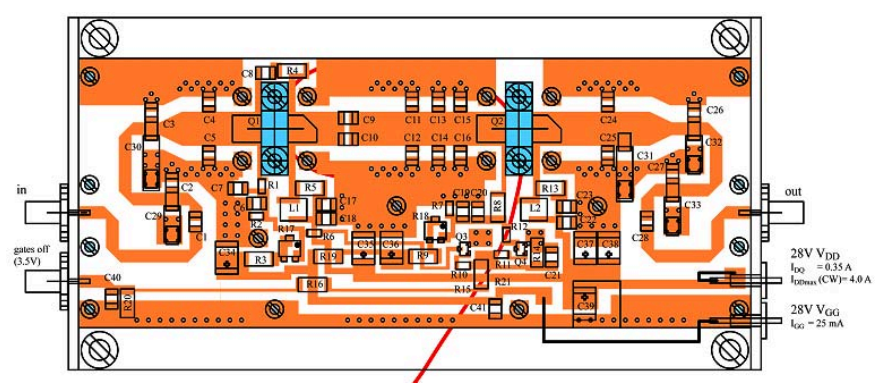

Figure 8: Simplified view of the power amplifier unit with two stages LDMOS MRF373 devices.

The series tuning is preferred over parallel tuning due to the low impedance levels. Figure 9 shows the simulated PAE, the gain and the output power versus frequency for the HPA. The HPA driver exhibits a constant gain and output power across the band and its measured PAE is around $65 \%$.
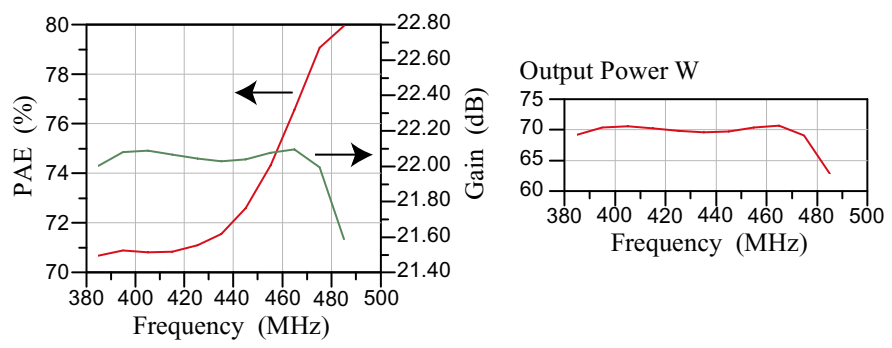

Figure 9: Simulated PAE, gain, and output power versus frequency for the HPA. 

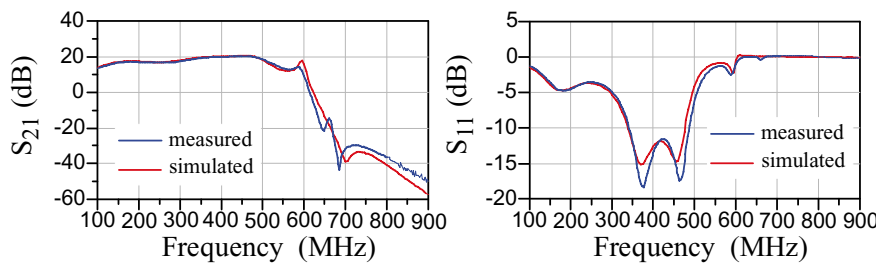

Figure 10: Measured and simulated gain and return loss of the driver circuit.

A comparison between measured gain and return loss for the driver stage indicate that our predictions are rather reliable, as indicated in Figure 10. Both measured parameters are in excellent agreement with simulated results using the Freescale LDMOS model. In the operating range of the radar the HPA exhibits a return loss of $>11 \mathrm{~dB}$ with a total $40 \mathrm{~dB}$ gain.

\section{CONCLUSIONS}

We have presented component design for an P-band ice sounding radar. The relative bandwidth of all components is around $20 \%$ at a return loss level of RL $>15 \mathrm{~dB}$. The components developed for the instrument are an antenna array, a high power amplifier, power dividers and a power switch. Results for some of these components presented in the paper demonstrate the successful implementation of the design. Other developed component results will be shown during the presentation.

The antenna is based on a stacked probe-fed microstrip patch with a coplanar patch excitation with $20 \%$ relative bandwidth at $15 \mathrm{~dB}$ return loss. Excellent agreement has been achieved between measurements and predictions for single element design. Both predicted and measured return loss and antenna patterns exhibit good agreement, respectively. Both polarization ports show perfect match both in measurements and simulations.

The HPA exhibits $>60 \%$ PAE at $70 \mathrm{~W}$ output power over the required bandwidth. This performance is achieved by series matching to the low terminal impedances in class B operation. The driver stages and the narrowband version of the HPA both exhibit PAE approaching $70 \%$. The driver and the HPA have good return loss and a constant gain across the frequency range. The driver gain varies only by $0.5 \mathrm{~dB}$ across the band and over the full power range. Excellent agreement is achieved between measurements and simulations in this case.

The lumped element Wilkinson dividers based on lefthanded/right-handed sections presented in this paper exhibit wideband operation with low measured and simulated losses of $<0.5 \mathrm{~dB}(0.2 \mathrm{~dB}$ for a standard lumped element Wilkinson divider) and good port matching. Phase unbalance between the ports in both circuits is $4^{0}$ and $2^{0}$, respectively. All these results are maintained during high power operation up to the tested power levels of $75 \mathrm{~W}$.

\section{ACKNOWLEDGMENT}

The partial financial support by the European Space Agency under contract no. 19307/05/NL/JA is acknowledged by the authors. The authors would also like to thank Röhm AG, Darmstadt, Germany for providing samples of ROHACELL. The excellent assistance by Dr. M. Böttcher at IMST during the single patch measurements is highly acknowledged.

\section{REFERENCES}

[1] J. Dall, N. Skou, A. Kusk, S. S. Kristensen, V. Krozer, "Design of an airborne P-band ice sounding radar", Proc. Workshop on Advanced RF Sensors for Earth Observation 2006, Noordwijk, The Netherlands, Dec. 2006.

[2] G. Picardi, D. Biccari, R. Seu, L. Marinangeli, W.T.K. Johnson, R.L. Jordan, J. Plaut, A. Safaenili, D.A. Gurnett, G.G. Ori, R. Orosei, D. Calabrese, E. Zampolini, "Performance and surface scattering models for the Mars Advanced Radar for Subsurface and Ionosphere Sounding (MARSIS)", Planetary and Space Science, Elsevier, No. 52, 2004.

[3] E. L. Christensen, N. Skou, J. Dall, K. Woelders, J. H. Jorgensen, J. Granholm, and S. N. Madsen, EMISAR: An Absolutely Calibrated Polarimetric L- and C-band SAR, IEEE Trans. Geoscience and Remote Sensing, vol. 36, no. 6, pp. 1852--1865, Nov. 1998.

[4] E. L. Christensen (ed), J. H. Joergensen, J. Dall, F. Hoeg, S. N. Madsen, J. Vidkjaer, J. Granholm, T. K Johansen, N. Skou, and K. Woelders, "SAR++ System Design Report", Tech. Rep. R 693, Technical University of Denmark, Dept. of Electromagnetic Systems, Jan. 2000.

[5] G. Jaworski and V. Krozer, "Broadband Matching of Dual-Linear Polarization Stacked Probe-Fed Microstrip Patch Antenna", Electronics Letters, vol.40, no.4, 2004.

[6] M. Limbach, "DLR E-SAR, New P-Band Subsystem - Technique and Results", European SAR working group, 7-8 October, 2003.

[7] Saab Ericsson Space, Jan. 2006, private communications.

[8] J. Huang, Z. Hussein, and A. Petros, "A Wide-Band Dual-Polarized VHF Microstrip Antenna for Global Sensing of Sea Ice Thickness", IEEE Conf. Proc., 2005.

[9] Gordon Mayhew-Ridgers. "Development And Modelling Of New Wideband Microstrip Patch Antennas With Capacitive Feed Probes", $\mathrm{PhD}$ thesis, University of Pretoria, 2004.

[10] T. Hirota, A. Minakawa, and M. Muraguchi, "Reduced-size branchline and rat-race hybrids for uniplanar MMIC's," MicrowaveTheory and Techniques, IEEE Transactions on, vol. 38, no. 3, pp. $270-275$, 1990.

[11] M. Chongcheawchamnan, N. Siripon, and I.D. Robertson, "Design and performance of improved lumped-distributed Wilkinson divider topology," Electronics Letters, vol. 37, no. 8, pp. 501 -503, 2001.

[12] H.S. Nagi, "Miniature lumped element 180/spl deg/ Wilkinson divider," 2003 IEEE MTT-S Microwave Symposium Digest, vol. 1, pp. 55-58 vol.1, 2003.

[13] M.A. Antoniades and G.V. Eleftheriades, "A Broadband Wilkinson Balun Using Microstrip Metamaterial Lines," IEEE Antennas and Wireless Propagation Letters, vol. 4, no. 1, pp. 209-212, 2005.

[14] Steven C. Cripps, Advanced Techniques in RF Power Amplifier Design, Artech House Publishers, 2002.

[15] Thomas Soerensen Yassin, "Development and Manufacturing of Direct Antenna Integrated RF Front- End for Ice Sounding Radar," M.S. thesis, Electromagnetic Systems, TU Denmark, Kgs. Lyngby, Denmark, 2006. 